\title{
Equipes de alta performance e o papel do líder para sua construção e
}

\section{desenvolvimento}

\author{
High-performance teams and the role of the leader in their construction and development
}

Equipos de alto desempeño y el rol del líder en su construcción y desarrollo

Recebido: 22/02/2021 | Revisado: 28/02/2021 | Aceito: 14/03/2021 | Publicado: 21/03/2021

Francisco das Chagas Araújo Coelho

ORCID: https://orcid.org/0000-0002-0862-2117 Assembleia Legislativa do Piauí, Brasil

E-mail: coelhocoe@yahoo.com.br

Ronny Batista de Sousa

ORCID: https://orcid.org/0000-0001-8549-4465

Faculdade de Educação Memorial Adelaide Franco, Brasil

E-mail: Ronnybatista@id.uff.br

\begin{abstract}
Resumo
A presente pesquisa versa sobre as equipes de alta performance e o líder. As equipes de trabalho efetivamente tornaram-se uma finalidade no mundo institucional, no presente estas equipes têm angariado ênfase pelo seu desempenho e a efeito disto verificou-se a utilidade de desenvolver equipes eficazes e de alta performance. Assim questionou-se, qual o papel do líder como construtor e avaliador de desempenho em equipes de alta performance? Sustentada pela hipótese de que o líder tem o papel de motivador, avaliador, gerenciador nas equipes de alta performance. A pesquisa tem como objetivo, compreender as distintas concepções teóricas sobre equipes de alta performance e observar o papel do líder como construtor e avaliador de desempenho. A fim de responder o objetivo proposto, utilizou-se de pesquisa bibliográfica de cunha qualitativo dedutivo. Os resultados indicam que, o líder possibilita o desenvolvimento e o crescimento da equipe, e estimula a resolução de conflitos, a participação, correlação de conhecimentos, competências e ações que provêm de seus componentes, favorecendo para que estas equipes sejam competentes e se tornem um diferencial para a instituição. Conclui-se que as instituições precisam adotar estruturas de equipes com foco no desempenho e um líder capacitado para guiar na direção a alta performance. Palavras-chave: Líder; Alta performance; Equipes; Desempenho; Resultados.
\end{abstract}

\begin{abstract}
The present research is about the high performance teams and the leader. Work teams have effectively become a goal in the institutional world, at present these teams have garnered emphasis on their performance and the effect of this has been found to be useful in developing effective and high performance teams. So he wondered, what is the role of the leader as a builder and evaluator of performance in high performance teams? Sustained by the hypothesis that the leader has the role of motivator, evaluator, manager in the high performance teams. The research aims to understand the different theoretical conceptions about high performance teams and to observe the role of the leader as a builder and performance evaluator. In order to answer the proposed objective, we used a qualitative deductive wedge bibliographic research. The results indicate that the leader enables the development and growth of the team, and stimulates conflict resolution, participation, correlation of knowledge, skills and actions that come from its components, favoring that these teams are competent and become a differential for the institution. It turns out that institutions need to adopt team structures that focus on performance and a leader capable of guiding the direction to high performance.
\end{abstract}

Keywords: Leader; High performance; Teams; Performance; Results.

\section{Resumen}

Esta investigación trata sobre equipos de alto rendimiento y el líder. Los equipos de trabajo se han convertido efectivamente en un propósito en el mundo institucional, en la actualidad estos equipos han ido enfatizando su desempeño y como resultado de esto se ha verificado la utilidad de desarrollar equipos efectivos y de alto desempeño. Entonces se preguntó, ¿cuál es el rol del líder como constructor y evaluador de desempeño en equipos de alto desempeño? Sustentados en la hipótesis de que el líder tiene el rol de motivador, evaluador, gerente en equipos de alto desempeño. La investigación tiene como objetivo comprender las diferentes concepciones teóricas sobre los equipos de alto desempeño y observar el rol del líder como constructor y evaluador del desempeño. Para dar respuesta al objetivo propuesto se utilizó una búsqueda bibliográfica deductiva cualitativa. Los resultados indican que, el líder posibilita el desarrollo y crecimiento del equipo, y fomenta la resolución de conflictos, participación, correlación de conocimientos, habilidades y acciones que provienen de sus componentes, favoreciendo que estos equipos sean 
competentes y se conviertan en un diferencial para La institución. Se concluye que las instituciones necesitan adoptar estructuras de equipo con enfoque en el desempeño y un líder capacitado para orientar hacia el alto desempeño.

Palabras clave: Líder; Alto rendimiento; Equipos; Rendimiento; Resultados.

\section{Introdução}

A presente pesquisa aborda o papel do líder para construção e desenvolvimento de equipes de alta performance. Desta forma, sabe-se que, implementar e desenvolver equipes de alta performance deve ser gerido e analisado frequente por um profissional capaz de desenvolver as competências da equipe, assim sendo, o líder é primordial para desenvolver equipes sinérgicas e de alto desempenho. Assim surge o seguinte questionamento, qual o papel do líder na construção e desenvolvimento de equipes de alta performance?

A liderança e equipes seguem agrupados, onde possuir uma equipe terá um líder que desenvolva o desenvolvimento da mesma, e quando estas equipes conseguirem a alta performance seu trabalho não estará selado, o líder será um atenuante e ajudará a equipe quando devido, pois, enquanto ensina o processo é internalizado e os resultados são visíveis (Leme, 2016).

A liderança é um sistema social em que se constituem ligação de controle entre pessoas. O meio desse sistema de interação humana é formado pelo líder ou líderes, seus gestores um caso e um tempo social. Pode-se verificar o sistema de liderança em inúmeras condições: na família, na escola, no esporte, na política, no trabalho, no comércio, na vida pública ou em espaços privados (Panzenhagen; Nez, 2018).

As equipes de alta performance podem se desenvolver num dos pilares de sustentação para qualquer instituição, sendo um fator importante na procura de vantagens competitivas. Para (2001, p.185) relacionado às equipes de trabalho, "elas são um elemento básico para o desempenho diante de um cenário de mudanças profundas". De outra forma, Ancona e Nadler (1988) apontam que as equipes são grupos de indivíduos compostos para criar sinergia, para crescimento a aplicação coordenada de conhecimento técnicos, com objetivo de que o desempenho do todo seja superior do que a soma de suas partes.

Neste cenário, o processo do reconhecimento de equipes de alta performance é um método que permite a empresa uma descrição de ter um elenco impulsionador na gestão no seu macro sistema produzindo melhoria de seus serviços, crescimento real da produtividade e vendas, máximo abrangência do cliente interno e externo, consolidação da sua imagem diante das concorrências. Trata-se por fim de um tratamento que procura a excelência nos produtos e serviços ofertados pela organização (Leme, 2016).

A pesquisa tem como objetivo geral, compreender as distintas concepções teóricas sobre equipes de alta performance e observar o papel do líder como construtor e avaliador de desempenho e específicos, elencar os principais estilos de liderança; identificar os principais conceitos de equipes de alta performance; evidenciar o papel do líder no desempenho das equipes de alta performance.

Construir uma equipe de alta performance não ação fácil, necessita de tempo, dedicação e estudos constantes. Tendo como passo inicial, selecionar, buscar profissionais com o perfil para somar com a equipe, na busca de excelentes resultados. O papel do líder neste campo é primordial, ele é a principal, sendo o líder que dá a direção e os demais seguem, sendo este o objetivo de qualquer líder de equipe (Dyer, 2017).

Considerando que as pessoas são o principal ativo das organizações e a liderança possui um papel fundamental para que elas (pessoas) alcancem as metas empresariais, essa pesquisa é importante porque é justamente através do líder que ocorre a administração do "conhecimento na empresa; a valorização, a satisfação e o desenvolvimento dos colaboradores, para que eles estejam integrados com os objetivos da organização e contribuam para o seu sucesso". 


\section{Metodologia}

Segundo Pereira et al. (2018, p. 95), "para escrever um artigo torna-se necessária a realização de uma pesquisa que inicialmente pode ser a bibliográfica para se tomar conhecimento ou se aprofundar no tema”. Na definição de Andrade (2009, p.111), pesquisa "é o conjunto de procedimentos sistemáticos, baseado no raciocínio lógico, que tem por objetivo encontrar soluções para problemas propostos, mediante a utilização de métodos científicos".

Desta forma, a presente pesquisa se caracteriza como bibliográfica de cunho qualitativo, que segundo Fonseca (2002) o referido trabalho é feito a partir do levantamento de referências teóricas já analisadas, e publicadas por meios escritos e eletrônicos, como livros, artigos científicos, páginas de web sites.

Qualquer trabalho científico inicia-se com um estudo bibliográfico, que permite ao pesquisador conhecer o que já se estudou sobre o assunto. A seguir, utiliza-se também a abordagem qualitativa. Ou seja, realiza-se uma análise interpretativa ao comparar os resultados deste estudo com os de outras pesquisas relacionadas ao tema, buscando identificar se houve melhoras ou não em função do estilo (s) de liderança (s) adotado (s). Para Gil (2017), na pesquisa qualitativa, realiza-se a interpretação dos fenômenos e a atribuição de significados básicos, sem a necessidade do uso de métodos e técnicas estatísticas.

\section{Estilos de Liderança}

Esta seção apresenta, inicialmente, os diversos estilos de lideranças apontados pela literatura e, a partir destes estilos, os três tipos básicos de lideranças: transformacional, transacional e laissez-faire.

Soares (2015) apresenta seis estilos de liderança utilizados no Brasil: Coercitivo, Dirigente, Afetivo, Democrático, Modelador e Treinador. O Coercitivo é vigilante e crítico, ácido e duro, colocando medo na equipe e atuam com ferramentas de punição à vista. O Dirigente foca no longo prazo e é visionário, direciona a equipe, diz o que espera de cada membro da equipe, e baseia-se em diálogo e comunicação. Recebe lealdade e alto desempenho da equipe. O Democrático busca tirar o máximo de cada profissional ao dividir responsabilidades e decisões. O estilo Modelador é muito exigente e detalhista, acreditando saber o caminho mais eficaz para realizar determinada atividade. E o líder Treinador busca identificar os pontos fortes e fracos da equipe, percebendo-se como um técnico de futebol.

Escorsin (2017) acrescenta mais três estilos de lideranças aos já apresentados por Soares (2015), que são: (1) permissiva ou laissez-faire - evita conflitos e busca agradar a todos o tempo todo; (2) transformacional-carismática - uso de visão pessoal e energia do líder para motivar e inspirar membros da equipe, tendo visão de futuro, sensibilidade ao ambiente e às necessidades dos membros; e (3) coach - foco no desenvolvimento além do profissional aos membros da equipe, inspirando o crescimento enquanto seres humanos.

Segundo Castro e Silva (2017), não há um modo ideal de liderar em toda e qualquer situação: os líderes com melhores resultados não fazem uso somente de um estilo de liderança, mas usam diversos estilos de acordo com cada situação. Entretanto, Bowditch e Buono (2016) salientam que os diversos estilos de lideranças podem ser agrupados sob três enfoques: liderança transacional; liderança transformacional e liderança laissez-faire. Inclusive, Batista, Kilimnik e Neto (2016) apontam que Bass e Avolio (1995) desenvolveram um instrumento (MLQ - Multifactor Leadership Questionnaire) de pesquisa para distinguir estilos de lideranças entre Transacional; Transformacional e Laissez-Faire. Os próximos parágrafos detalham os três estilos/abordagens de liderança.

A liderança transacional baseia-se em uma relação de troca de esforços por recompensa (Batista, Kilimnik, Neto, 2016). Ou seja, "a Liderança Transacional se encontra em uma interação entre líder e seguidores com recompensas aos seguidores por promoverem melhor desempenho nas tarefas" (Batista; Kilimnik; Neto, 2016, p.26). Segundo Castro e Silva (2017), a liderança transacional mantém a cultura com ênfase nas trocas entre trabalho, recompensa e punição, com base em métodos e técnicas e relações fundamentadas pelo contrato. Essa troca entre o líder e o seguidor Batista, Kilimnik, Neto (2016) 
pode ser de ordem política, econômica ou psicológica, mas não havendo uma ligação prolongada entre as partes.

Para Barbosa, Gambi e Gerolamo (2017), no estilo transacional, há o estabelecimento de metas, o monitoramento e a verificação dos resultados. Após estabelecer metas e designar as tarefas, a liderança pode monitorar constantemente as atividades (gerenciamento por exceção ativo) e corrigir e/ou punir os desvios padrões e erros dos liderados, ou o líder pode aguardar passivamente (gerenciamento por exceção passivo) e tomar ações somente depois da ocorrência dos erros. Em função disso, recompensa-se o liderado com desempenho satisfatório e pune-se àquele que apresentou um mau desempenho.

A liderança transformacional relaciona-se ao comportamento no qual o líder busca identificar necessidades e motivações latentes em seus liderados, agindo no sentido de motivar a equipe no alcance de elevados padrões de desempenho (Barbosa; Gambi; Gerolamo, 2017). Para Batista, Kilimnik e Neto (2016, p.26), na liderança transformacional, "o líder preocupa-se com o progresso e o desenvolvimento dos seus seguidores", atuando para a criação de um clima organizacional regido pela confiança entre membros da equipe e da equipe com o líder, com foco no atendimento aos objetivos da empresa.

Segundo Barbosa, Gambi e Gerolamo (2017), a liderança transformacional é composta por quatro dimensões: carisma, inspirador, estimulação intelectual e atenção individual. O líder carismático ganha confiança, fidelidade, consideração e respeito dos liderados, focando no futuro; o inspirador comunica a visão da empresa com seus próprios exemplos (modelo); e adquire admiração, respeito e confiança dos liderados. O líder intelectual inspira o desenvolvimento inovações e incentiva a crítica construtiva. Por fim, a atenção individual diz respeito ao apoio/suporte que o líder dá aos seus subordinados, dando-lhes feedback frequente do desempenho.

Gomes, Xavier e Lemos (2015) apontam que a liderança transformacional se caracteriza por inspirar os seguidores a optar pelo interesse da equipe a interesses individuais, cuidar do bem-estar dos membros da equipe com visão da empresa; e interligar valores da organização com os valores dos colaboradores da equipe ou da empresa como um todo. No entanto, Gomes, Xavier e Lemos (2015, p.39) registra que a liderança transformacional "[...] por ser muito burocrática e pouco eficiente; [...] transforma o funcionário num seguidor passivo, onde há apenas relação de troca entre empregado e organização". Isso pode gerar "um vínculo fraco baseado apenas na autoridade burocrática" (Gomes; Xavier; Lemos, 2015, p.39).

Para Batista, Kilimnik e Neto (2016), a liderança transformacional é indicada para ambientes mais turbulentos e que enfrentam mudanças frequentes, sendo a liderança transacional mais apropriada para ambientes mais estáveis. Esse posicionamento difere das colocações de Auler (2014, p.186) ao ressaltarem que a líder precisa tomar atitudes de acordo com sua equipe "estando ciente de que quanto mais participativo for o estilo de liderança adotado, maior será a probabilidade dele e sua equipe atingirem níveis ótimos de sucesso".

Laissez-faire deriva do francês e significa "deixai fazer, deixai ir, deixai passar". O estilo de liderança laissez-faire caracteriza-se por um comportamento do líder como neutro e despreocupado. O líder não intervém nas atividades do liderado e também não com as necessidades e/ou realizações dos membros da equipe: "[...] então, há ausência de liderança, uma vez que nesse estilo parece haver um nível significativo de negligência do desenvolvimento da equipe" (Batista; Kilimnik; Neto, 2016, p.26). Para Barbosa, Gambi e Gerolamo (2017), o laissez-faire está ligado à insatisfação, ao conflito, à inefetividade, à passividade, a não fixação clara de metas, expectativas, objetivos, métodos de trabalho à sua equipe.

No entendimento de Oliveira, Duarte e Bastos (2018), no estilo laissez-faire, o líder simplesmente não toma atitude alguma diante das situações que surgem no decorrer das atividades, somente manifesta-se quando os problemas tomam maiores proporções de gravidade. Diferentemente da liderança transacional e transformacional nos quais há um ambiente com objetivos estabelecidos, na liderança laissez-faire isso não é possível, "pois o líder não utiliza uma estratégia, adia a tomada de decisões, ignora as suas obrigações e poder" (Oliveira; Duarte; Bastos, 2018, p.268). 


\section{Equipes de Alta Performance}

As organizações no presente aspiram equipes com diferencial competitivo demonstrado por sua alta performance, e que assim forma os resultados podem ser obtidos de maneira eficaz e eficiente, as equipes de alto desempenho segundo Dyer $e t$ al. (2017, p. 23) definem como sendo:

aquelas compostas de membros cujas habilidades, atitudes e competências lhes permitem atingir as metas da equipe. Em equipes de alto desempenho, os membros definem as metas, tomam decisões, comunicam-se, administram os conflitos e solucionam problemas em uma atmosfera de incentivo e confiança para atingir seus próprios objetivos. Além disso, os membros desta equipe estão cientes de suas próprias forças e fraquezas e tem a capacidade de mudar quando necessário para melhorar o desempenho do grupo.

As equipes de alta performance manifestam a capacidade de trabalhar em equipe, onde seus próprios componentes regem e traçam as medidas além de se alto desenvolverem procurando aumentar o desempenho da equipe. As equipes de alta performance são aquelas que atravessam os limites tradicionais pelos benefícios obtidos. Seus componentes apresentam perspectivas notáveis e, por isto, serve como incentivos determinantes para a alta performance. Visam medidas de desempenho intensamente altos, e deste modo seus membros precisam ter conhecimentos, habilidades e atitudes que valham aos objetivos da equipe. As condições ambientais e a ausência de muitos recursos podem influenciar o desempenho, mas uma equipe de alta performance excede os problemas ambientais (Luecke, 2010).

Para que as equipes elucidem a competência do trabalho em equipe é fundamental internalizar três elementos que a estrutura: conhecimento, habilidades e atitudes, que segundo Santiago (2016, p. 84 - 85) explica algumas particularidades que desenvolvem as competências de equipes, sendo,

1) Conhecimentos que favorecem a expressão da competência: Administração de conflitos, comunicação, confiança, cultura organizacional, feedback, gestão do conhecimento, personalidade, tipos psicológicos, comportamento humano, poder, trabalho em equipe; 2) Habilidades que favorecem a expressão da competência: capacidade de conviver com as diferenças, capacidades de identificar os comportamentos do grupo, escutar e perceber o implícito; 3) Atitudes que favorecem a expressão da competência: autoconfiança, cooperação, conciliação, cortesia, dinamismo, disponibilidade, disciplina, empatia, entusiasmo, ética, flexibilidade, humildade, iniciativa, justiça, objetividade, persistência, proatividade, resiliência, respeito, responsabilidade, segurança, sensibilidade, transparência e tolerância.

Os componentes da equipe devem distinguir os conflitos e solucioná-los, bem como conseguir comunicar-se uns com os outros, produzindo elos de confiabilidade, entendendo os valores e princípios da organização, dar e receber feedback, controlar os conhecimentos e utilizá-los da melhor forma provável. Seus membros devem perceber que seu comportamento e personalidade provocam nas relações, sendo fundamental cada membro se auto-administrar e saber trabalhar em equipe (Leme, 2016).

No atual mundo em que as instituições demandam oferecer um diferencial para permanecer no mercado em que exercem, investem no valor de suas equipes. Desta forma, procuram equipes que desenvolvam um diferencial competitivo demonstrado por sua alta performance, e que desta maneira os efeitos possam ser obtidos de modo eficiente, ágil e competente (Luecke, 2010).

Uma equipe de alta performance: "é um conjunto que corresponde todas as situações da equipe real e apresenta membros que estão também extremamente compromissados com o desenvolvimento e sucesso uns dos outros" (Leme, 2016, p. 45). O autor ainda explica que Equipe de alta performance, tende a todos as possibilidades de equipe real e tem um compromisso importante entre seus componentes com o objetivo de desenvolvimento pessoal de cada um.

\section{Papel do Líder para Construção e desenvolvimento das Equipes de Alta Performance}

A liderança está vigente em todos os pontos e condições, seja na vida pessoal ou institucional. No livro O Monge e o 
Executivo, James Hunter (2004, p. 25) indica que liderança é "a habilidade de influenciar pessoas para trabalharem entusiasticamente visando atingir aos objetivos identificados como sendo para o bem comum".

A liderança é um fator importante que gera e aplica a energia das pessoas, lhes proporciona uma direção e sincroniza seus esforços. Com efeito, representa indicador fundamental do potencial de uma empresa, diferentemente dos resultados financeiros, que apenas indicam onde a empresa já esteve. Uma forte liderança faz com que uma boa empresa seja ainda melhor da mesma forma que, com certeza, uma fraca liderança reduz o seu potencial e, com o tempo, o destrói (Charan, 2008, p. 9).

Um sujeito mostra sua prática de liderar não somente por suas específicas características pessoais, porém no contexto do qual se encontra. O líder é percebido pelo grupo como proprietário dos meios para satisfação de suas carências, é um estrategista que dirige as pessoas para compreender seus fins. No entanto, estas capacidades, não estão associadas ao poder e, sim, a autoridade, adquirida com amor, dedicação e sacrifício.

O líder é muito fundamental em todas as instituições, pois o mesmo dirige, determina, treina e avalia o desempenho da equipe para que as metas sejam obtidas, realiza grande influência nos primeiros momentos de liderança e quando a equipe se tornar uma equipe de alta performance o mesmo passará a ser um atenuador da equipe e suas obrigações serão partilhadas com a equipe por meio de do treinamento (Tonet et al., 2012). Nas primeiras etapas do desenvolvimento da equipe, a mesma demanda de um líder coach, que na língua inglesa, significa treinador, o ele ajudará a equipe a se ampliar e atingir os frutos da organização.

O gestor, no papel de coach, estabelece com os membros da equipe um relacionamento para apoiar o seu processo de aprendizagem e desenvolvimento, seja objetivando a mudança de aspectos indesejáveis do desempenho, seja visando à aquisição de novas competências ou outros objetivos afins (Tonet et al., 2012, p. 87).

Ampliar o potencial de cada pessoa representa atuar com seus pontos fortes, apenas desta forma o desempenho será bom, porém até que atinja o grau maior é necessário muito interesse, treinamento e estudo do método. A instituição precisa de trabalhadores produtivos, com competências que favoreçam com os frutos da mesma, considerado que o desempenho da equipe é avaliado pela eficiência com que seus componentes conseguem obter as finalidades e quanto mais conhecimento, habilidade e atitude os componentes apresentarem mais produtiva será a equipe.

O líder tem de indicar as metas, os fins que a equipe precisa atingir e também avaliar o desempenho da mesma. As metas é o resultado que a instituição espera que a equipe atinja, é a quantificação do trabalho em equipe e a análise do desempenho desta, por isso os componentes devem estar conscientes desta obrigação e conter as competências fundamentais para sua execução. Sobre as metas da equipe e de seus componentes Luecke (2010, p. 39), diz que,

Devem estar alinhadas com as metas organizacionais e acrescenta que o trabalho de cada integrante também deve estar alinhado por um sistema de recompensas. Ao trabalhar em equipe os membros esperam que seus esforços sejam recompensados e que a organização reconheça o desempenho de cada integrante, oferecendo-lhes condições salariais, bonificações e prêmios de produção condizentes com a dedicação e os resultados de toda a equipe.

Para Leme (2016, p. 103), "o sistema de remuneração com foco em competências é a forma de recompensar financeiramente o colaborador de acordo com as competências que o mesmo é capaz de entregar a organização".

As instituições operam como uma forma transacional, neste caso os trabalhadores prestam serviços a empresa e a mesma recompensa financeiramente pelo trabalho disposto. E quanto mais conhecimento e habilidades o trabalhador dominar tanto será a busca deste no mercado de trabalho, sendo um elemento ideal para integrar e aumentar o desempenho da equipe e da instituição. "Quando a equipe completar a tarefa e atingir o padrão de desempenho estabelecido, é preciso recompensar imediatamente. Isso gera um ciclo positivo, pois a concretização da tarefa merece ser reconhecida com um prêmio" (Bruce, 2016, p. 36).

Adiante, as instituições devem zelar por um campo agradável, onde os componentes sintam-se à vontade para 
executar suas funções, oferecendo os recursos e condições precisas para motivar as equipes em seu campo de trabalho. Para que as instituições mantenham os talentos é fundamental valorizá-los financeiramente, emocionalmente é um contexto que satisfaça suas necessidades, assim, apenas nesse sentindo os trabalhadores estarão empenhados com os objetivos organizacionais. Assim é fundamental acompanhar, direcionar e avaliar o desempenho da equipe. Donnellon (2006, p. 92 - 97), mostra um meio de avaliar o desempenho da equipe por meio das seguintes variáveis: "a) utilize medidas de desempenho adequadas; b) Fatores de avaliação do desempenho; c) Selecione os métodos de avaliação; d) Revise o desempenho individual dos integrantes da equipe; e) Recompense sua equipe".

As medidas de desempenho são os critérios utilizados para mensurar o resultado do trabalho em equipe, pode também ser entendida como o processo de avaliação por seus usuários. Existem diversas formas de medir o desempenho da equipe e o mesmo pode ser observado pela concretização das tarefas e alcance dos objetivos, bem como a satisfação dos clientes, o lucro obtido, qualidade nos serviços e produtos oferecidos e prazos acordados.

Para Dyer et al. (2017, p. 23) os fatores que influenciam diretamente no desempenho da equipe são: "a) Contexto; b) Composição; c) Competências; d) Mudança (change) $\mathrm{O}$ contexto da equipe diz respeito à influência que o ambiente interno $\mathrm{e}$ externo exerce sobre o desempenho da equipe, podendo contribuir ou mesmo prejudicar o crescimento e o desenvolvimento da equipe".

O desempenho provém dos resultados obtidos pela aplicação de métodos utilizados para a avaliação da equipe e do próprio gestor. Chiavenato (2016) salienta que os principais métodos de avaliação de desempenho dividem-se em tradicionais e modernos. Nos tradicionais, destacam-se: escala de classificação; comparações de empregados; lista de verificação; ensaios de livre forma; entrevistas; e incidentes críticos. E nos métodos modernos, Chiavenato (2016) ressalta os centros de avaliação; administração por objetivos; e contabilidade de valores humanos. Em cada tópico, avaliam-se pontos relacionados à produção; qualidade; conhecimento do trabalho; cooperação; características individuais; compreensão das situações; criatividade/engenhosidade; capacidade de realização; causas, origem e motivos de certos desempenhos; registros de características extremas que podem levar ser a resultados positivos ou negativos; resultados projetados e atingidos, auto avaliação, etc. No entanto, cada empresa desenvolve o método mais apropriado às circunstâncias, à história e os objetivos da organização.

Palácios e Brito (2017) sugerem que a avaliação de desempenho se relaciona à avaliação das competências e este processo precisa levar em conta (1) conhecimentos; (2) habilidades - capacidade; e (3) atitude - intencional. A competência é vista pelos autores como uma reunião sistematizada de conhecimentos, habilidade e atitudes observadas no desempenho do quadro de pessoal em certa circunstância de uma empresa. Neste conceito, o desempenho busca agregar valor aos profissionais e à empresa como um todo. Entretanto, Rodrigues et al. (2017) salientam que há diversas formas de mensurar o desempenho individual ou da equipe e cabe à empresa utilizar o que atenda às suas especificidades. Eles apontam ser importantes, na avaliação de gestores, a mensuração de resultados; o comportamento; o processo de monitoramento da equipe; e a comunicação interpessoal do gestor.

Neste contexto, apesar da existência de diversos métodos de avaliação de desempenho, a atuação do líder impacta diretamente de modo que pessoas aplicam seus conhecimentos, habilidades e atitudes (Escorsin, 2017). Mesmo tendo metas e objetivos pré-estabelecidos, é pelo meio do líder que a equipe irá executar as ações para alcançar os resultados almejados, ou não. As competências (habilidades, conhecimentos e atitudes) da equipe podem refletir a própria competência do líder, uma vez que aquele é desenvolvido e monitorado por este, e os resultados podem ser (in) satisfatórios quando existe uma sinergia entre gestor e equipe.

Desta forma, as equipes de alto desempenho produzem vantagem competitiva e agregação de valor à cadeia produtiva da instituição, o desempenho é consequência do alargamento do potencial de cada componente da equipe, e das competências e 
capacidade de se adequar ao ambiente onde estão postos.

O papel do líder é primordial para que a equipe cresça e atinja à alta performance, se os resultados não forem continuamente analisados a equipe não irá compreender em que momento está e nem as medidas para desenvolver seu desempenho. O líder possibilita o crescimento e o desenvolvimento da equipe, provoca a resolução de conflitos, a cooperação, a complementaridade de práticas, habilidades e ações que provêm de seus componentes, contribuindo para que estas equipes consigam chegar à seus objetivo e se tornem um diferencial competitivo para a instituição empresarial (Luecke, 2010).

Dias e Gomes (2015) destacam que a liderança influencia profundamente no desempenho da equipe em termos ligados à satisfação, criação de novas ideias, inovação, coesão da equipe, comunicação, resolução de conflitos, ética, confiança, etc. Por isso, é essencial que a organização descubra o estilo de liderança mais indicado a sua realidade e trabalhe neste sentido, visando aperfeiçoar o desempenho da equipe e da liderança, com foco no pleno alcance dos resultados organizacionais.

\section{Considerações Finais}

As equipes de alta performance produzem benefício sendo eles na competitividade e aglomeração de valor à cadeia produtiva da instituição, o desempenho é consequência da maximização da capacidade de cada componente da equipe, e das habilidades e capacidade de se adequar ao meio onde estão postos.

O papel do líder é fundamental para que a equipe avance e alcance à alta performance, se os fins não forem constantemente observados a equipe não saberá em que período está e nem as formas para melhorar. O líder possibilita a evolução e o desenvolvimento da equipe, e provoca a solução de discussões, a cooperação, correlação de conhecimentos, prática e atitudes que provêm de seus componentes, favorecendo para que estas equipes sejam eficientes e se transformem em um diferencial concorrente para a organização.

Desta forma, as instituições precisam trabalhar com um modelo de equipes com foco em desempenho e um líder capaz de gerir estas equipes em direção a alta performance alcançando por meio destes recursos maior produtividade e lucratividade.

O líder é uma peça importante para construção, manutenção e longevidade de uma equipe de alta performance, sua capacidade de contagiar, motivar seus subordinados deve ocorrer de forma espontânea e natural, clara, sem excessos, programar ações, tomar decisões, gerir e delegar com exatidão, ser participativo, devem ser propriedades do líder moderno.

Por fim, sugere-se novos estudos sobre a temática, principalmente pesquisas de campo, uma vez que a estrutura para o sucesso de uma equipe de alta performance inicia na sua construção, na escolha dos componentes, existindo lugar somente para os mais capacitados, com perfil inovador, desenvolvido no cenário do que a instituição espera que o mesmo possa somar ao desenvolvimento de um modo geral.

\section{Referências}

Andrade, M. M. (2009). Introdução à metodologia do trabalho científico: elaboração de trabalhos na graduação. (9a ed.), Atlas.

Auler, D. (2014). Os estilos de liderança na gestão dos serviços bancários. Revista de Carreiras e Pessoas. 4(2), $178-187$.

Barbosa, F. M., Gambi, L. N. \& Gerolamo, M. C. (2017). Liderança e gestão da qualidade - um estudo correlacional entre estilos de liderança e princípios da gestão da qualidade. Revista Gest. Prod., 24(3), 438-449.

Batista, N., Kilimnik. Z. \& Neto, M. (2016). Influência dos estilos de liderança na satisfação no trabalho: um estudo em uma entidade de fins não econômicos. Revista Navus, 6(3), 24-39.

Bowditch, J., \& Buono, A. (2016). Elementos de comportamento organizacional. Cengage Learning,

Bruce, A. (2016). Como motivar sua equipe. (8a ed.), Sextante. 
Research, Society and Development, v. 10, n. 3, e42310313216, 2021

(CC BY 4.0) | ISSN 2525-3409 | DOI: http://dx.doi.org/10.33448/rsd-v10i3.13216

Castro, P., \& Silva, F. M. (2017). Liderança organizacional em uma incubadora de empresas de base tecnológica. Revista Navus, 7(3), 71-85.

Charan, R. (2018). O líder criador de líderes. (7a ed.), Elsevier.

Dias, M., Borges, G. (2015). Estilos de liderança e desempenho de equipes no Setor Público. Revista Eletrônica de Administração, 21(1), 200-221.

Donnellon, A. (2006). Liderança de equipes: escolha sua equipe, comunique as metas, defina as funções, crie um clima de confiança: soluções práticas para os desafios do trabalho. 1ed. Elsevier.

Dyer, W. G., Dyer, W. G. J. \& Dyer, J. H. (2017). Equipes que fazem a diferença (Team Building): Estratégias comprovadas para desenvolver equipes de alta performance. 1 ed. Saraiva.

Escorsin, A. P., \& Wagner, C. (2017). Liderança e desenvolvimento de equipes. InterSaberes.

Gomes, C., Xavier, L. \& Lemos, Z. (2015). A Liderança e a Retenção de Servidores na Gestão Pública. Revista de Carreiras e Pessoas, 5(1), $34-73$.

Katzenbach, J., Smith, D. (2001). Equipes de Alta Performance. (2a ed.), Campus.

Leme, R. (2016). Avaliação de desempenho com foco em competência: a base para remuneração por competência. Qualitymark.

Luecke, R. (2010). Criando equipes. (2a ed,), Record.

Oliveira, M., Duarte, M., \& Basto, M. (2018). Percepção dos colaboradores sobre os estilos de liderança e sua influência no desempenho: estudo de caso na Santa Casa da Misericórdia. Repositório da Unidade do Algarve, 262-285.

Palácios, K. P., \& Brito, L. S. (2017). Impacto das Competências de Equipes sobre o Desempenho. Psicologia. Revista Teoria e Pesquisa, 33(1), 1-10.

Panzenhagen, M. (2019). Chefia e liderança na gestão pública: algumas reflexões. http://www.unifia.edu.br/revista_eletronica/revistas/g estao_foco/artigos/ano2012/chefia_lideranca.pdf.

Rodrigues, A. et al. (2017). Gestão de desempenho: validação de um instrumento de medida. Revista de Ciências da Administração, 19(47), 57-74.

Santiago, A. C. Q. (2016) As Competências das Pessoas: potencializando seus talentos. (8a ed.), DVS Editora.

Soares, M. (2015). Liderança e desenvolvimento de equipes. (2a ed.), Person.

Tonet, H. et al. (2012). Liderança e gestão de pessoas em ambientes competitivos. Editora FGV. 